This item was submitted to Loughborough's Research Repository by the author.

Items in Figshare are protected by copyright, with all rights reserved, unless otherwise indicated.

\title{
Impact of changing frequency standards on a domestic electricity consumer
}

PLEASE CITE THE PUBLISHED VERSION

https://doi.org/10.1109/UPEC.2019.8893633

PUBLISHER

IEEE

VERSION

AM (Accepted Manuscript)

\section{PUBLISHER STATEMENT}

(c) 2019 IEEE. Personal use of this material is permitted. Permission from IEEE must be obtained for all other uses, in any current or future media, including reprinting/republishing this material for advertising or promotional purposes, creating new collective works, for resale or redistribution to servers or lists, or reuse of any copyrighted component of this work in other works.

\section{LICENCE}

All Rights Reserved

\section{REPOSITORY RECORD}

Chinyemba, Tinashe, Farhad Anvari-Azar, and Dani Strickland. 2019. "Impact of Changing Frequency Standards on a Domestic Electricity Consumer". Loughborough University.

https://hdl.handle.net/2134/14188508.v1. 


\title{
Impact of changing frequency standards on a domestic electricity consumer
}

\author{
T Chinyemba, F Anvari-Azar, D Strickland \\ Wolfson School \\ Loughborough University \\ Loughborough, UK
}

\begin{abstract}
The UK electricity operates at $50 \mathrm{~Hz} \pm 1 \%$. To keep the frequency within these limits it is necessary to purchase frequency response services. These services need to be adequate to deal with a power loss of $1 \mathrm{GW}$. Additional pressures in keeping the frequency stable come from reducing grid inertia requiring faster acting response. This paper considers an alternative approach around changing the standards on frequency. Modern technology is no longer so reliant on the $50 \mathrm{~Hz}$ electricity grid for timing and most modern machines use power electronic converters for control. This paper, therefore, investigates changing the frequency limits and the nominal frequency with different voltage levels and determines the impact of this on domestic loads.
\end{abstract}

Index Terms-Demand Side Management, Demand Side Response, Distribution Networks, Frequency Limits, Frequency Response

\section{INTRODUCTION}

National grid, the UK's transmission operator, has a legal obligation to maintain a nominal $50 \mathrm{~Hz}$ frequency on the electricity network with a tolerance of $1 \%$ [1]. There are certain events which define exceptions for which the frequency is allowed to exceed its limits; (1) Significant Events which are any credible fault such as a single item of power plant or a double line failure, that causes an active power imbalance between $300 \mathrm{MW}$ to $1000 \mathrm{MW}$ where the system frequency shall not deviate by more than $0.5 \mathrm{~Hz}$. (2) Abnormal Events are any credible faults which result in an active power imbalance between $1000 \mathrm{MW}$ to $1800 \mathrm{MW}$ where the frequency shall not deviate by more than $0.8 \mathrm{~Hz}$.

Due to decarbonisation targets there has been a focus on shifting from traditional sources of generation to renewable energy generation. This has resulted in a reduction in system inertia as synchronous generators have been replaced by power electronic based converter technology. A reduction in system inertia makes the electricity grid hard to control as there is the potential for deviations outside of frequency bounds and increases to the Rate of Change of Frequency (ROCOF) which can act to trip embedded generation [2]. Traditional frequency controls can be slow to respond to disturbances and may be unable to prevent large frequency deviations on the grid.
National Grid use a variety of balancing services to control the frequency with different response times associated with each service. Examples include STOR and Firm Frequency Response (FFR) also known as Primary, Secondary and High response modes. This FFR response can be static (the generator is either on or off based on a threshold and must respond within 30 s) or dynamic - the generator continually changes output to follow the frequency and must respond within 10s. For larger generators $(>1000 \mathrm{MW})$ a requirement of the generation license is that these generators are required to assist with balancing the Network through the grid code and need to be able to both increase and decrease generation if called upon as part of their mandatory frequency response [3].

For smaller generation this is not a requirement, but these forms of generation can apply to participate in the balancing markets to generate income. It is also practical to undertake frequency response using Demand Side Response (DSR) also sometimes referred to as Demand Side Management (DSM). The majority of DSR is done by switching loads on and off in response to the frequency [4]. These FFR frequency services are expensive and total expenditure on commercial frequency response was estimated as $>£ 70$ million in 2018 found by checking the contracted frequency each month. The faster the response the more expensive it is to purchase. Figure 1 shows the accepted bid availability prices in 2018 for dynamic and non-dynamic services. FFR dynamic services are expected to detect a frequency event within $2 \mathrm{~s}$ and ramp up to full output within $10 \mathrm{~s}$, while the figure for non-dynamic is $30 \mathrm{~s}$. The prices indicate that it is around 5 times more expensive to purchase dynamic response compared to static response. The contracted dynamic service is larger than the non-dynamic service as shown in Figure 2. If the proportion of dynamic to non-dynamic service can be altered there could be good financial savings.

Prior to GPS and accurate timing, many clocks ran on grid frequency necessitating its tight control. Additionally, prepower electronics and motor drive development. The torque, speed control and losses in online motors were impacted by frequency. With the introduction of accurate GPS timing and the changeover to power electronic controlled machines - the question is - are there any reason to maintain these tight boundaries? Or can they be loosened to save on FFR costs? 


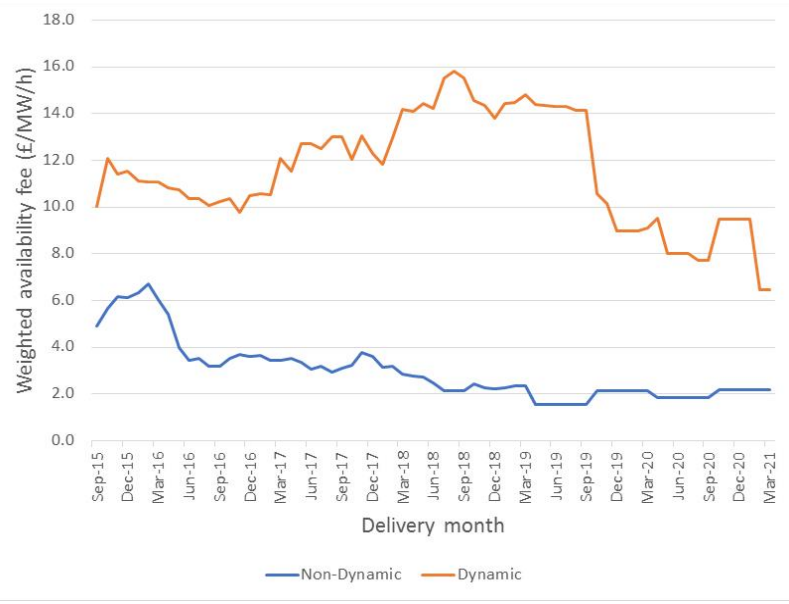

Figure 1. Shows the accepted bid availability in 2018 FFR auctions, for dynamic and non- dynamic services

\section{Contracted volume $=$ contracted $\mathrm{mw}^{*}$ \\ number of available hours in a day $/ 24$}

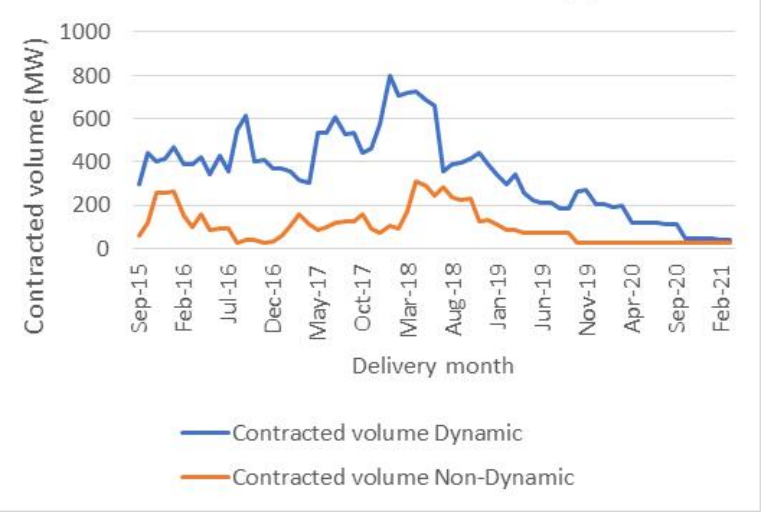

Figure 2. Contracted volume of dynamic and non-dynamic frequency response

This paper is novel because it looks from a domestic consumer perspective at what would happen if the frequency bands that National Grid adheres to are no longer deemed a requirement in todays society and were relaxed. A further scope for re-considering the frequency at domestic level is that many appliances are sold in a wide range of countries and can be transported between the USA (at $60 \mathrm{~Hz}$ ) and the UK (at $50 \mathrm{~Hz}$ ) and can be used in both locations successfully.

Section II looks at the estimated FFR reserve that would be saved if the frequency bounds were moved and no longer so tightly bound. Section III presents the methodology used to test the loads at different voltage and frequency, Section IV presents the results from a range of load types. Section V discusses whether there is scope to change the National Grid frequency from a domestic perspective.

\section{FFR RESERVES AT DIFFERENT CONDITIONS}

This paper uses the methodology presented in references [5], [6] looking at the change in frequency at different inertias for a $1 \mathrm{GW}$ step change in load. To understand the effect of loss of infeed due to a significant event. To model frequency:
Where

$$
\frac{d f}{d t}=\frac{P_{\text {in }}-P_{\text {out }}}{2 S H} f=\frac{\Delta P}{2 I} f
$$

$P_{i n}$ is the active power input to the power system (MW)

$P_{\text {out }}$ is the active power output to the power system (MW)

$\Delta P$ is the active power imbalance (MW)

$\mathrm{S}$ is the apparent power rating of the machines connected to the power system (MVA)

$\mathrm{H}$ is the inertia constant connected to the power system (s)

I is the system Inertia (MVA.s)

$\mathrm{f}$ is the system frequency $(\mathrm{Hz})$

Equation (1) is a differential equation describing the change in frequency with time which can be solved using numerical techniques, in this case Euler's Forward method implemented in Matlab 2018b using the method in Figure 3. The key difference in this paper compared to other work is the use of different initial conditions to represent a slackening of standards. These values are then carried forward to the experimental testing.

The objectives of the simulations are to analyse and quantify the required level of primary response under a different range of initial grid frequencies for a range of grid inertias from 160,000 MVA.s to 360,000 MVA.s. The following assumptions have been made.

1. Primary response occurs with a $2.0 \mathrm{~s}$ detection and $10 \mathrm{~s}$ ramping to full power

2. An event of a $1000 \mathrm{MW}$ interconnector trip

3. The frequency does not fall below $49.2 \mathrm{~Hz}$ and the calculated ROCOF does not exceed $0.5 \mathrm{~Hz} / \mathrm{s}$

The modelling results in Figure 4 shows that to guarantee that the frequency won't drop below $49.2 \mathrm{~Hz}$ with a low inertia and $50 \mathrm{~Hz}$ nominal frequency, up to $1.6 \mathrm{GW}$ of holding reserve may be required with the stated conditions above. If the nominal frequency was shifted upwards to $51 \mathrm{~Hz}$ or even $52 \mathrm{~Hz}$ then this requirement would no longer exist, and there would be less requirement to operate the primary reserve within the first $10 \mathrm{~s}$ opening the door to slower responding services which could be potentially cheaper.

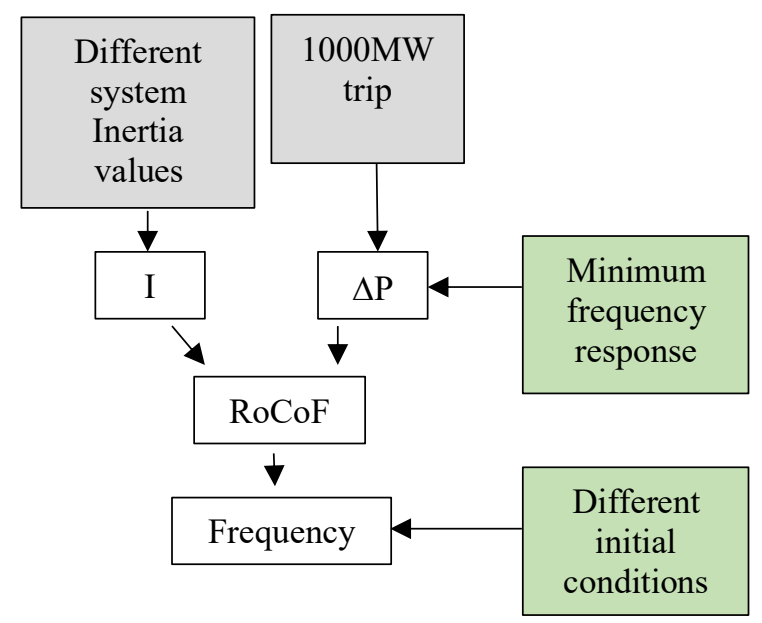

Figure 3. Functional Frequency Ramp Model 
Cost indications indicate that (excluding mandatory FFR) that reducing the commercial dynamic response to the level of the non-dynamic response and vice versa has the potential to save National Grid nearly £40m per year.

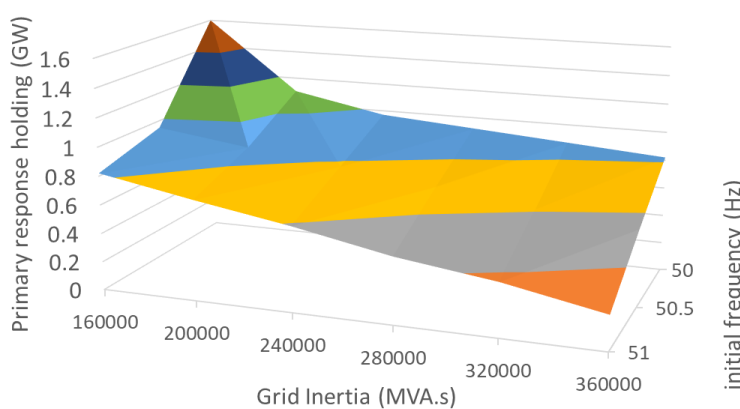

Figure 4. Required Minimum Frequency Response

However, to understand if such a departure from current frequency limits would be an issue it is necessary to investigate the impact of this frequency change under different voltage conditions on the load. In this paper, a range of common domestic appliances are investigated.

\section{COMMON DOMESTIC LOADS}

The following table contains a list of ratings (both UK and US) of different domestic appliances that can be commonly found on domestic properties [7]-[10].

A range of domestic loads from Table I were tested at different voltage and frequency to understand if there was any scope for increasing the frequency range targets within the UK from a domestic perspective.

TABLE I. DOMESTIC LOADS

\begin{tabular}{|c|c|c|c|c|c|}
\hline Appliance & $\begin{array}{c}\text { Typical } \\
\text { Ratings } \\
(W)\end{array}$ & Time & Appliance & $\begin{array}{c}\text { Typical } \\
\text { Ratings } \\
(W)\end{array}$ & Time \\
\hline Kettle & $\begin{array}{c}2200- \\
3000\end{array}$ & Min & TV's & $125-450$ & $\mathrm{Hr}$ \\
\hline Toasters & $700-1500$ & Min & $\begin{array}{c}\text { Cooking } \\
\text { Hood } \\
\text { Extractor }\end{array}$ & 143 & $\mathrm{Hr}$ \\
\hline Deep fryer & 1200 & Min & $\begin{array}{c}\text { Waste } \\
\text { Disposal } \\
\text { Units }\end{array}$ & 460 & Min \\
\hline Fridge & $40-120$ & Cont. & $\begin{array}{c}\text { Ventilation } \\
\text { Systems }\end{array}$ & $150-360$ & $\mathrm{Hr}$ \\
\hline $\begin{array}{l}\text { Fridge- } \\
\text { Freezer }\end{array}$ & $200-400$ & Cont. & $\begin{array}{c}\text { Underfloor } \\
\text { Heating }\end{array}$ & $\begin{array}{c}3000- \\
30 \mathrm{~m} 2 \\
\text { coverage }\end{array}$ & $\mathrm{Hr}$ \\
\hline $\begin{array}{c}\text { Tumble } \\
\text { dryer }\end{array}$ & $\begin{array}{c}2000- \\
3000 \\
\end{array}$ & $\mathrm{Hr}$ & $\begin{array}{l}\text { SKY/Virgin } \\
\text { Media box }\end{array}$ & $30-40$ & Cont \\
\hline $\begin{array}{l}\text { Washing } \\
\text { Machine }\end{array}$ & $\begin{array}{l}1200- \\
3000\end{array}$ & $\mathrm{Hr}$ & $\begin{array}{c}\text { Instant Hot } \\
\text { Tap }\end{array}$ & 1430 & Min \\
\hline $\begin{array}{l}\text { Oil filled } \\
\text { Radiator }\end{array}$ & $\begin{array}{l}1500- \\
2500\end{array}$ & $\mathrm{Hr}$ & $\begin{array}{c}\text { Pressure } \\
\text { Washer }\end{array}$ & 1400 & $\mathrm{Hr}$ \\
\hline Microwave & $600-1500$ & Min & $\begin{array}{c}\text { Air } \\
\text { conditioner }\end{array}$ & $700-1400$ & $\mathrm{Hr}$ \\
\hline Dishwasher & $\begin{array}{c}1050- \\
1500\end{array}$ & $\mathrm{Hr}$ & $\begin{array}{c}\text { Garden } \\
\text { shredder }\end{array}$ & 500 & Min \\
\hline
\end{tabular}

\begin{tabular}{|c|c|c|c|c|c|}
\hline Iron & $\begin{array}{c}1000- \\
18000\end{array}$ & Min & Hand Driers & 1800 & $\mathrm{Min}$ \\
\hline Towel Rail & $250-400$ & $\mathrm{Hr}$ & $\begin{array}{c}\text { Steam } \\
\text { Cleaner }\end{array}$ & 2000 & $\mathrm{Hr}$ \\
\hline $\begin{array}{c}\text { Desktop } \\
\text { Computer }\end{array}$ & $80-150$ & $\mathrm{Hr}$ & $\begin{array}{c}\text { Laptop } \\
\text { Charger }\end{array}$ & $45-85$ & $\mathrm{Hr}$ \\
\hline $\begin{array}{c}\text { Vacuum } \\
\text { Cleaner }\end{array}$ & $500-1200$ & $\mathrm{Min}$ & $\begin{array}{c}\text { Electric } \\
\text { Oven }\end{array}$ & $\begin{array}{c}2000- \\
2200\end{array}$ & $\mathrm{Hr}$ \\
\hline $\begin{array}{c}\text { Dehumidifi } \\
\text { er }\end{array}$ & $300-700$ & $\mathrm{Hr}$ & $\begin{array}{c}\text { Electric } \\
\text { Hob }\end{array}$ & $\begin{array}{c}1000- \\
2000\end{array}$ & $\mathrm{Hr}$ \\
\hline $\begin{array}{c}\text { Slow } \\
\text { Cooker }\end{array}$ & 250 & $\mathrm{Hr}$ & $\begin{array}{c}\text { Electric } \\
\text { Lawn } \\
\text { Mower }\end{array}$ & $500-1500$ & $\mathrm{Hr}$ \\
\hline $\begin{array}{c}\text { Ice cream } \\
\text { Maker }\end{array}$ & 20 & $\mathrm{Hr}$ & $\begin{array}{c}\text { Electric } \\
\text { Shower }\end{array}$ & $\begin{array}{c}7000- \\
10500\end{array}$ & $\mathrm{Min}$ \\
\hline $\begin{array}{c}\text { Bread } \\
\text { Maker }\end{array}$ & 450 & $\mathrm{Hr}$ & $\begin{array}{c}\text { Power } \\
\text { Shower }\end{array}$ & $\begin{array}{c}8500- \\
10500\end{array}$ & $\mathrm{Min}$ \\
\hline $\begin{array}{c}\text { Coffee } \\
\text { Machine }\end{array}$ & 1450 & $\mathrm{Min}$ & $\begin{array}{c}\text { Sandwich } \\
\text { and Panni } \\
\text { Press }\end{array}$ & $\begin{array}{c}1000- \\
2000\end{array}$ & $\mathrm{Min}$ \\
\hline $\begin{array}{c}\text { Food } \\
\text { Processor }\end{array}$ & 500 & $\mathrm{Min}$ & $\begin{array}{c}\text { Deep Fryer } \\
1800\end{array}$ & $\mathrm{Min}$ \\
\hline Blender & 2000 & $\mathrm{Min}$ & $\begin{array}{c}\text { Crepe } \\
\text { Maker }\end{array}$ & 1000 & $\mathrm{Min}$ \\
\hline Food Mixer & 1500 & $\mathrm{Min}$ & Rice Cooker & 700 & $\mathrm{Hr}$ \\
\hline Air Fryer & 1400 & $\mathrm{Min}$ & Hot Tub & 2000 & $\mathrm{Hr}$ \\
\hline
\end{tabular}

\section{A. Test Set Up}

Figure 5 shows the single line diagram of the setup used to investigate the how load changes with respect to voltage and frequency, while Figure 6 shows a photo of the test set up.
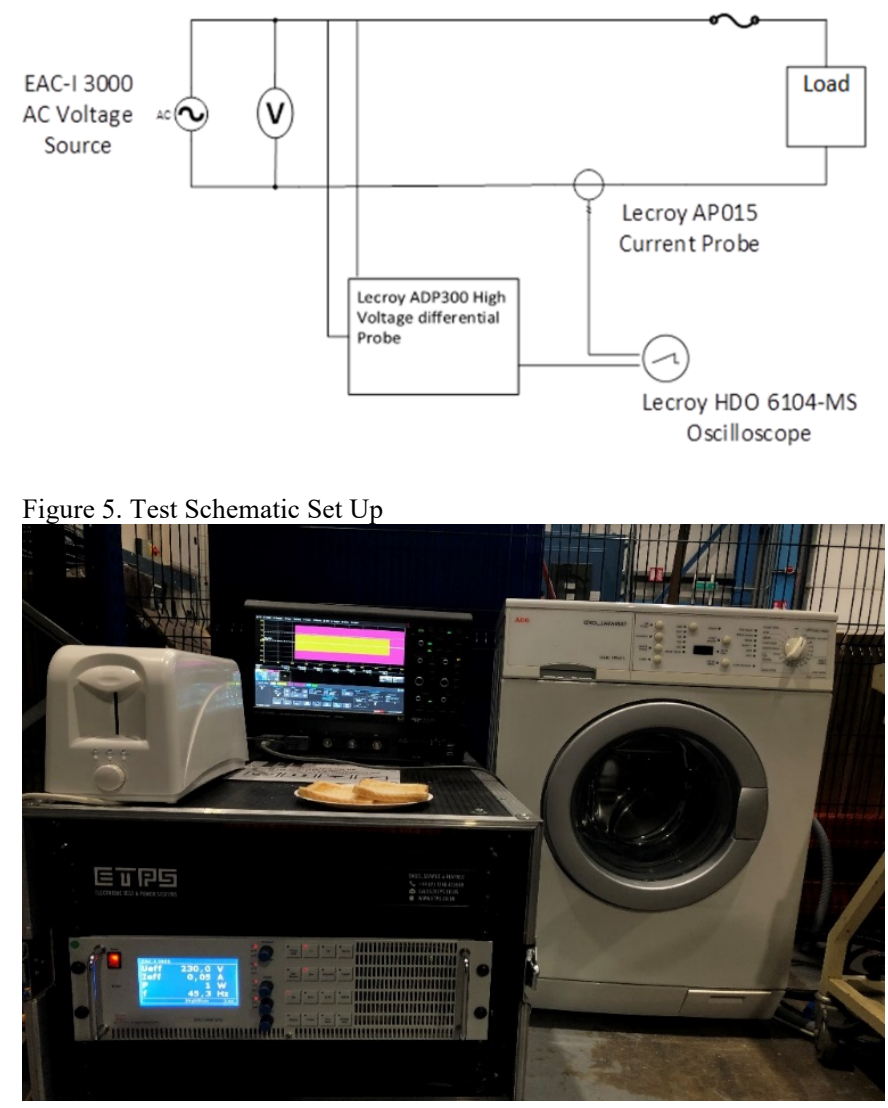

Figure 6. Test Rig photo 


\section{EXPERIMENTAL RESULTS}

Domestic devices that were tested included a toaster, washing machine, fridge freezer, kettle, iron and bread maker. As part of this testing a control was used to compare overall performance in conjunction with the voltage, current and power measurements.

\section{A. Toaster}

A WMTTW4S002 Wm Morrisons own brand toaster was tested between $45 \mathrm{~Hz}$ and $55 \mathrm{~Hz}$. Each frequency was tested with a range of voltages between $220 \mathrm{~V}$ and $245 \mathrm{~V}$. Results shown in Figure 7 indicate that as the voltage increased so did the power consumption. The frequency did not have an affect on the power consumption of the toaster. The control test was to look at the impact on the toast colour for a fixed setting under the different conditions. These showed that frequency had little impact, but the reduction in voltage resulted in less power to the toaster and therefore a lighter toast as seen in Figure 8. There were no obvious issues with operating the toaster over a range of frequencies from $45 \mathrm{~Hz}-55 \mathrm{~Hz}$.

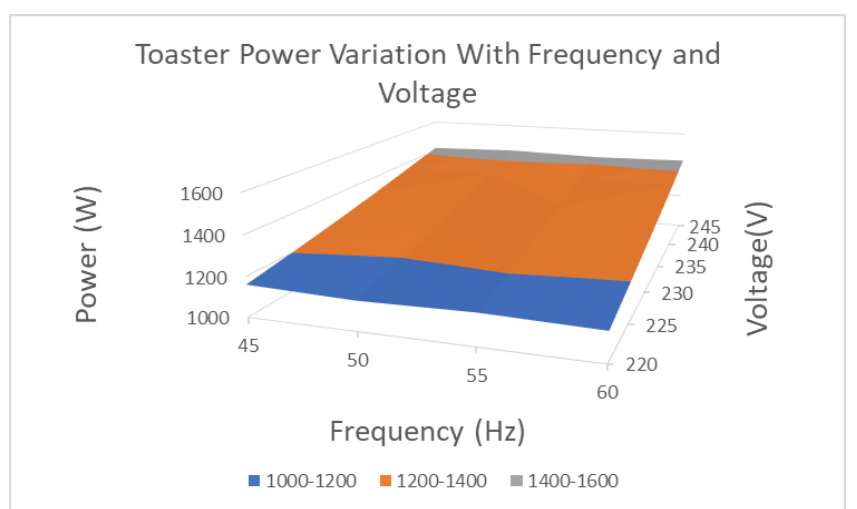

Figure 7. Toaster Power Variation with Frequency and Voltage

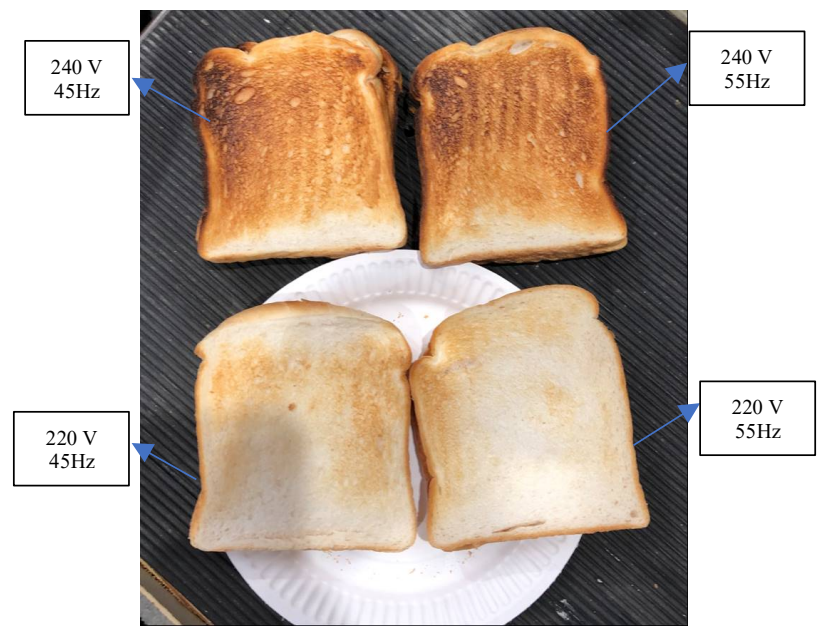

Figure 8. Toast produced under different conditions

\section{B. Washing Machine}

An AEG OKO LAVAMAT 72640 washing machine was tested from $48 \mathrm{~Hz}$ to $52 \mathrm{~Hz}$, with a range of voltages from $220 \mathrm{~V}$ to $240 \mathrm{~V}$. The washing machine was placed on a 40 -degree easy-care programme, the programme consists of main wash, rinse and spin. The washing machine follows the sequence of a 53 minutes main wash, followed by a 22-minute rinse cycle and concluded with a 5-minute spin cycle. The washing machine was not tested at $45 \mathrm{~Hz}$ and $55 \mathrm{~Hz}$ like the other appliances, as it was found that when the frequency is out the bounds of $47 \mathrm{~Hz}-53 \mathrm{~Hz}$, an error message was displayed on the interface display panel.

There is little perceptible difference in current with frequency as shown in Figure 9. At higher frequency, the reactance increases, the current reduces and the power factor lags resulting in a total power consumption that remains largely unchanged as shown in Figure 10. At higher voltage, the current reduces and the power factor lags still further.

The control test was to look at the impact on a ketchup stained cotton for a fixed setting under the different conditions. The cotton samples showed that frequency and voltage had little impact on the wash, shown in Figure 11. There were no obvious issues with operating the Washing Machine over a range of frequencies from $48 \mathrm{~Hz}-52 \mathrm{~Hz}$.
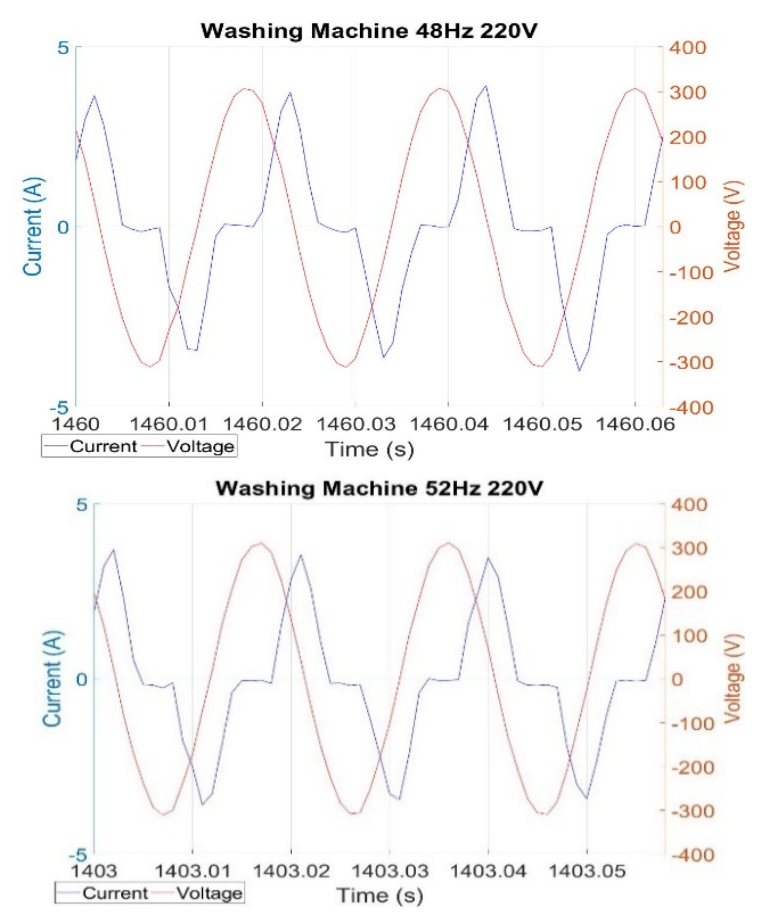

Figure 9. Voltage and Current on the rinse cycle

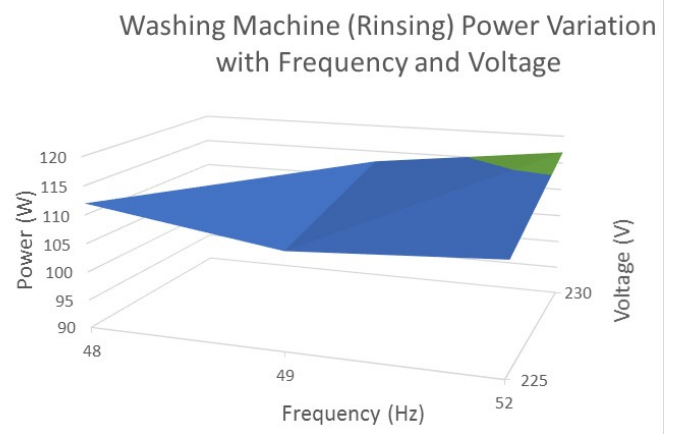

Figure 10. Washing Machine Power Variation with Frequency and Voltage during the rinse cycle 

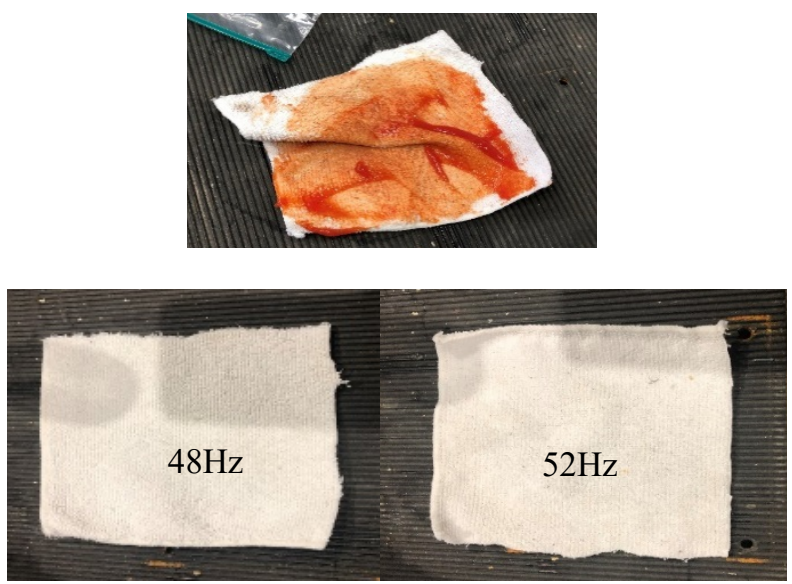

Figure 11. A Ketchup stained cotton cloth before and after the wash at $48 \mathrm{~Hz}$ and $52 \mathrm{~Hz}$

\section{Fridge Freezer}

An Iceline 24368 Fridge Freezer was tested between $45 \mathrm{~Hz}$ and $55 \mathrm{~Hz}$, for a voltage range between $220 \mathrm{~V}$ and $240 \mathrm{~V}$. The fridge freezer uses a pump to help cool the system. As this is driven by a motor there is an associated lagging power factor as shown in Figure 12. For the purposes of these experiments the fridge freezer was started from room temperature to force the pump to be on continuously. During the course of the experiments the power factor, varied between 0.51 and 0.94 cancelling out the reduction in current magnitude. The power consumption with respect to voltage and frequency is shown in Figure 13.

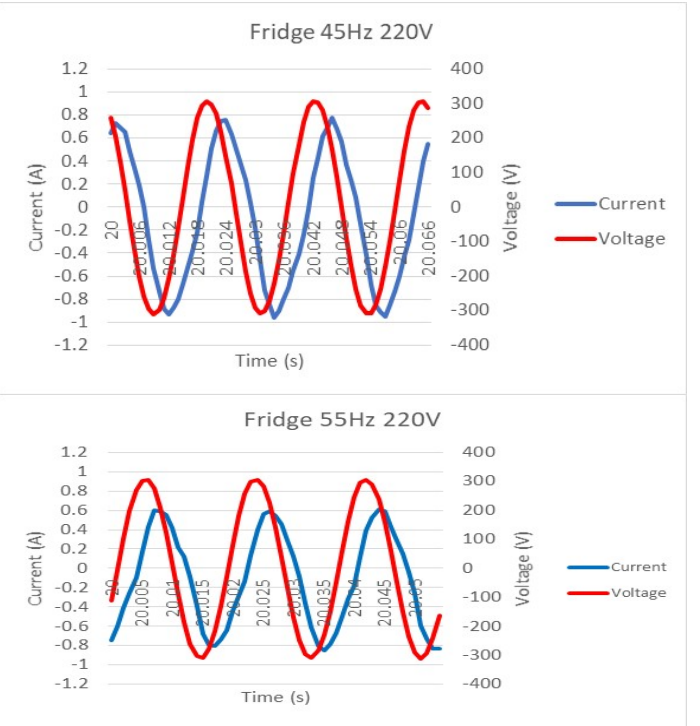

Figure 12. Voltage and Current of Fridge Freezer when cooling

\section{Kettle}

A Cookworks 12106 travel kettle was tested between $45 \mathrm{~Hz}$ and $55 \mathrm{~Hz}$ with voltage variation between $220 \mathrm{~V}$ and $240 \mathrm{~V}$. As expected for a resistive element, the kettle's power consumption was not affected by changes in the frequency. Time for the kettle to boil with a fixed amount of water remained constant for each frequency at the same voltage level. The power consumption with respect to frequency and voltage is shown in Figure 14.
Fridge Freezer Power Variation with Frequency and Voltage

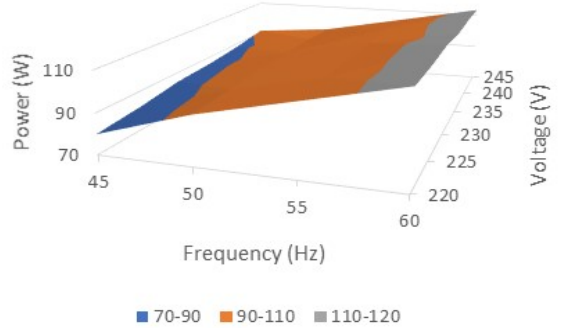

Figure 13. Fridge Freezer Power Variation with Frequency and Voltage

Kettle Power Variation with Frequency and Voltage

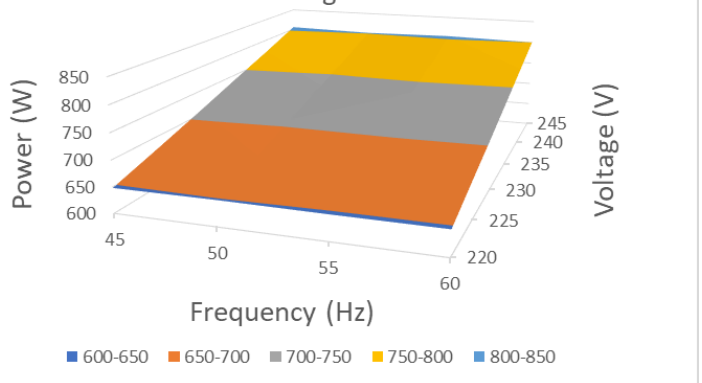

Figure 14. Kettle Power Variation with Frequency and Voltage

E. Iron

A 043269 Sainsbury's own brand iron was tested between $45 \mathrm{~Hz}$ and $55 \mathrm{~Hz}$ with a voltage range between $220 \mathrm{~V}$ and $240 \mathrm{~V}$. The iron operates in conjunction with a thermostatic switch which turns the heating element on and off with temperature. The iron is unaffected by the variations in frequency. The iron is active approximately $20 \%$ of the time when the iron is on. The power consumption variation is shown in Figure 15 for when the iron is consuming power.

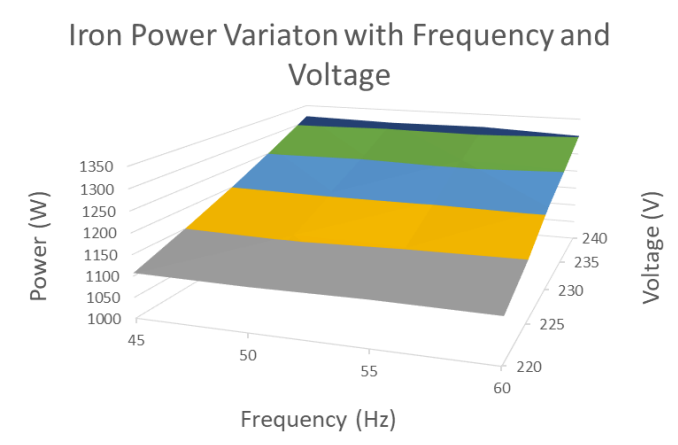

- 1000-1050 =1050-1100 =1100-1150 = 1150-1200 =1200-1250 =1250-1300 -1300-1350

Figure 15. Iron Power Variation with Frequency and Voltage 


\section{F. Bread Maker}

A Goodmans GHB161A Bread Maker was tested at $45 \mathrm{~Hz}$ and $55 \mathrm{~Hz}$, with a voltage variation between $220 \mathrm{~V}$ and $240 \mathrm{~V}$. The Bread Maker was set to the turbo setting, this cycle lasted approximately 2 hours. The cycle was divided into the categories of mixing, proving and baking. Each lasting 23, 47 and 50 minutes respectively. The Bread maker has a $65 \mathrm{~W}$ rated motor and $450 \mathrm{~W}$ heater. During the mixing stage a motor driven mixing blade was used. The power variation during mixing is shown in Figure 16.

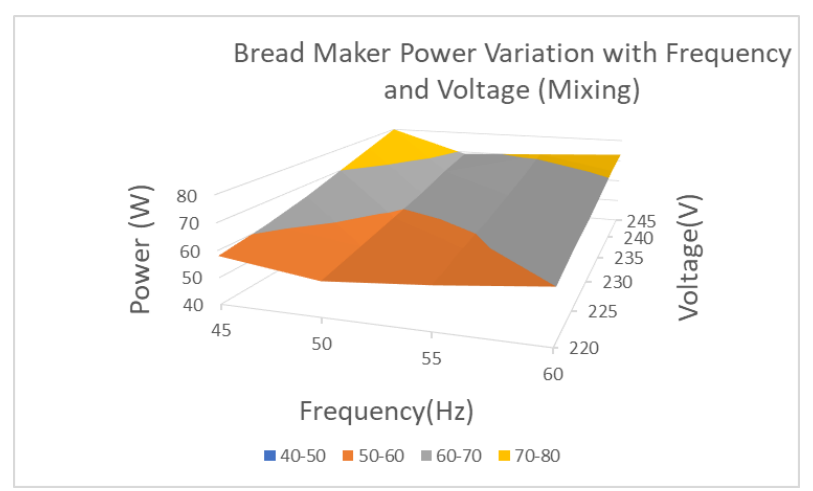

Figure 16. Bread Maker Power Variation with Frequency and Voltage (Mixing)

During the proving and baking stages, the heating element is operated by a thermostatic switch. The power variation during proving is shown in Figure 17. The frequency does not affect the power consumption during the proving stages as the heater is operating at unity power factor with heating element control.

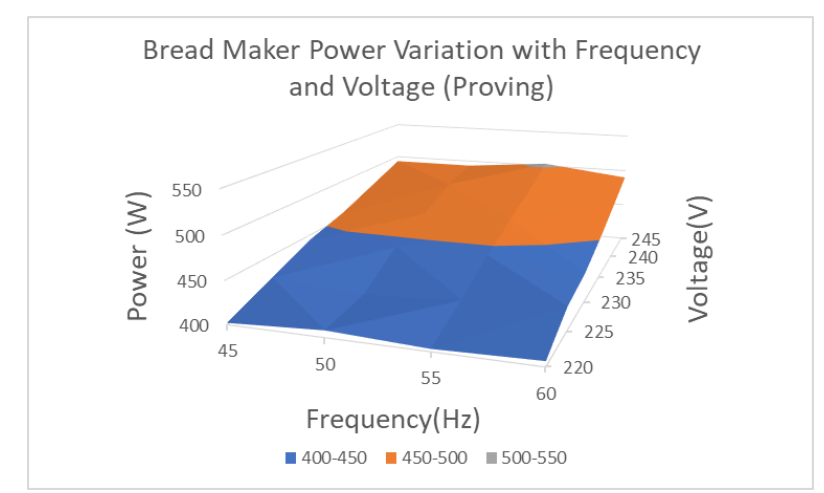

Figure 17. Bread Maker Power Variation with Frequency and Voltage (Proving)

During the baking stage, the thermostatic switch increases its activity, this is in order to increase and maintain a higher temperature for baking.

\section{CONCLUSION}

As power electronic embedded generation increases on the UK's grid. National grid may need to increase spend on balancing services. This paper has established that the is some scope for National Grid to save money on the balancing services by changing the nominal frequency and allowing a higher level of frequency deviation from the perspective of a domestic customer. The majority of domestic loads are resistive and could still perform $\pm 10 \%$ of the nominal frequency. On the other hand, motor-based appliances could be operated at $\pm 6 \%$ of the nominal UK frequency.

Future work will have to be done to establish what affect the varying frequency has on industrial customers and the transmission and distribution network before potential savings in balancing services could be realised in this way.

\section{ACKNOWLDGEMENTS}

The authors would like to acknowledge the help provided by ETPS Ltd for their help purchasing the voltage source.

\section{REFERENCES}

[1] National Grid, "Frequency Response Services," National Grid, 2018. [Online]. Available: https://www.nationalgrideso.com/balancingservices/frequency-response-services. [Accessed: 15Nov-2018].

[2] National Grid Electricity Sytem Operator, "Future Requirement for Balancing Services," National Grid Electricity Sytem Operator. [Online]. Available: https://www.nationalgrideso.com/sites/eso/files/docume nts/Requirements Report 2016.pdf. [Accessed: 14-Mar2019].

[3] N. Grid, "Mandatory Frequency Response," 2018. [Online]. Available: https://www.nationalgrid.com/sites/default/files/docume nts/Mandatory Frequency Response Guide v1.1.pdf. [Accessed: 02-Nov-2018].

[4] D. Hirst, "GB2361118 - Responsive load system," GB0008666.0, 2001.

[5] D. Cooke, Alexander Forkasiewicz, Kane Strickland, "Energy Storage for Enhanced Frequency Response Services," 2017 52nd Int. Univ. Power Eng. Conf., 2017.

[6] K. Forkasiewicz, M. Coldwell, A. Cross, and D. Strickland, "Meeting Frequency Response Requirements with Uncertain System Inertia - a UK perspective," 2016 IEEE Int. Conf. Renew. Energy Res. Appl., 2016.

[7] M. Newborough and P. Augood, "Demand-side Management Opportunites for the UK Domestic Sector," IEE Proc. - Gener. Transm. Distrib., vol. 146, no. 3, 1999.

[8] A. Ashourpouri, A. Ghosh, and S. Rajakaruna, "Demand dispatch through Appliance Management Unit in a semismart home," IECON 2016 - 42nd Annu. Conf. IEEE Ind. Electron. Soc., 2016.

[9] M. Pipattanasomporn, M. Kuzlu, S. Rahman, and Y. Teklu, "Load Profiles of Selected Major Household Appliances and Their Demand Response Opportunities," IEEE Trans. Smart Grid, vol. 5, no. 2, 2014.

[10] I. Laicane, D. Blumberga, A. Blumberga, and M. Rosa, "Evaluation of household electricity savings. Analysis of household electricity demand profile and user activities," Energy Procedia, vol. 72, pp. 222-229, 2015. 